\title{
Article
}

Subscriber access provided by King Abdullah University of Science and Technology Library

\section{A fine-tuned fluorinated MOF addresses the needs for trace CO2 removal and air capture using physisorption.}

Prashant M. Bhatt, Youssef Belmabkhout, Amandine Cadiau, Karim Adil, Osama

Shekhah, aleksander shkurenko, Leonard J. Barbour, and Mohamed Eddaoudi

J. Am. Chem. Soc., Just Accepted Manuscript • DOI: 10.1021/jacs.6b05345 • Publication Date (Web): 08 Jul 2016

Downloaded from http://pubs.acs.org on July 17, 2016

\section{Just Accepted}

"Just Accepted" manuscripts have been peer-reviewed and accepted for publication. They are posted online prior to technical editing, formatting for publication and author proofing. The American Chemical Society provides "Just Accepted" as a free service to the research community to expedite the dissemination of scientific material as soon as possible after acceptance. "Just Accepted" manuscripts appear in full in PDF format accompanied by an HTML abstract. "Just Accepted" manuscripts have been fully peer reviewed, but should not be considered the official version of record. They are accessible to all readers and citable by the Digital Object Identifier (DOI®). "Just Accepted" is an optional service offered to authors. Therefore, the "Just Accepted" Web site may not include all articles that will be published in the journal. After a manuscript is technically edited and formatted, it will be removed from the "Just Accepted" Web site and published as an ASAP article. Note that technical editing may introduce minor changes to the manuscript text and/or graphics which could affect content, and all legal disclaimers and ethical guidelines that apply to the journal pertain. ACS cannot be held responsible for errors or consequences arising from the use of information contained in these "Just Accepted" manuscripts. 


\section{INTRODUCTION}

Mitigating the amount of the $\mathrm{CO}_{2}$ released in the atmosphere, directly correlated to the global warming, remains an ongoing challenge that requires a concerted worldwide effort from academia, industry and governments alike. Inopportunely, the worldwide energy needs have doubled the fossil fuel consumption in the last two decades, ${ }^{1-11}$ as a result of the eminent economic growth and the enhanced quality of living in emerging countries, and thus provoking the manifest and amplified global carbon dioxide emission. The foreseen deployment of a relatively cleaner alternative energy sources, e.g. solar, renewable and nuclear, to meet the increasing global energy demand, while lessening or eliminating the $\mathrm{CO}_{2}$ emission as a result of deserting the dominant use of the fossil fuel, is still universally debated and implausible in the near future. ${ }^{1-11}$ In view of that and while preparing for the looked-for fossil-fuel free transition, it is evidently necessary to develop new technologies and materials for the effective and energy-efficient carbon dioxide $\left(\mathrm{CO}_{2}\right)$ capture in a wide range of concentrations. Explicitly, point-source carbon capture and storage (CCS) can be regarded as a plausible solution sanctioning the sustainable use of fossil fuels in power, steel and cement production plants, while direct air capture (DAC) can address and remediate the $\mathrm{CO}_{2}$ emissions from mobile-sources such as automobiles and airplanes. ${ }^{1-11}$ Markedly, the DAC offers a great prospective to remotely capture the emitted $\mathrm{CO}_{2}$ at a different distant location and time.

It is to note that the $\mathrm{CO}_{2}$ capture from air using the chemical adsorption technology has been deployed, for over seven decades, to maintain a safe level of $\mathrm{CO}_{2}$ in confined spaces such as space shuttles and submarines, where access to fresh air is limited. ${ }^{12,13}$ Nevertheless, the $\mathrm{CO}_{2}$ concentrations and the associated $\mathrm{CO}_{2}$ quantities to the DAC (400 ppm $\mathrm{CO}_{2}$, worldwide average of $54 \mathrm{~kg} /$ person/day) and to the point-source CCS (7$15 \% \mathrm{CO}_{2}$, worldwide average of $38 \mathrm{~kg} /$ person/day) entail a relatively larger scale footprint and/or an excessive energy penalty than the requisites for the $\mathrm{CO}_{2}$ capture in confined spaces $\left(1-5 \% \mathrm{CO}_{2}\right.$ and $1 \mathrm{~kg} /$ person/day). ${ }^{1-11}$ Perceptibly, the cost associated to the $\mathrm{CO}_{2}$ capture in confined spaces is not a disturbing concern, as the compulsory objective is the effective removal of $\mathrm{CO}_{2}$ and the subsequent procurement of the indispensable clean air.

Noticeably, the low $\mathrm{CO}_{2}$ concentration in air $(400 \mathrm{ppm})$ and the compulsory low $\mathrm{CO}_{2}$ level in confined spaces $(<0.5 \%)$ position chemical adsorbents, such as aqueous alkylamine solutions and lithium hydroxide $(\mathrm{LiOH})(80-120 \mathrm{~kJ} / \mathrm{mol})$, as the conventional benchmark materials, with a high $\mathrm{CO}_{2}-$ selectivity even in the presence of water vapor, for the carbon 
capture in diluted $\mathrm{CO}_{2}$ concentrations ${ }^{8}$ Nevertheless, largescale widespread of the chemically driven separation approach is hampered by the prohibitive high-energy requirement for the $\mathrm{CO}_{2}$ desorption/regeneration process. Markedly, there is a need to develop a new generation of highly $\mathrm{CO}_{2}$-selective physical adsorbent materials with a moderate $\mathrm{CO}_{2}$ heat of adsorption, i.e. below $60 \mathrm{~kJ} / \mathrm{mol}^{3,14-17}$ Consequently, such a looked-for adsorbent will pave the way to an affordable, effective and energy-efficient recovery of $\mathrm{CO}_{2}$ and renders the DAC competitive and self-sustainable. Considerately, the aerospace industry recognized the advantages of the physisorption-based separation and recently shifted their efforts to the utilization of recyclable physical adsorbents, such as the zeolite $5 \mathrm{~A}\left(\mathrm{Ca}^{2+}\right)$ and the SAPO-34 $\left(\mathrm{Sr}^{2+}\right)$, for the capture of $\mathrm{CO}_{2}$ in confined spaces. ${ }^{18,19}$ Typically, the aforementioned physical adsorbents exhibit a moderate $\mathrm{CO}_{2}$ heat of adsorption of 45-50 $\mathrm{kJ} / \mathrm{mol}$ and a recyclable $\mathrm{CO}_{2}$ uptake of $9-15 \mathrm{~cm}^{3}(\mathrm{STP}) / \mathrm{g}(1.7-$ $2.9 \mathrm{wt} \%)$ at $1300 \mathrm{ppm}$. Nonetheless, their overall performance is inadequate and ineffective in the presence of water vapor due to their relative low tolerance to water.

Metal organic frameworks (MOFs), a tunable class of porous solid-state materials, are regarded to offer prospective solutions to various challenges pertaining to gas storage and gas separation. ${ }^{20-29}$ Evidently, the modular and hybrid character of MOFs permit the fine-tuning of their affinity for $\mathrm{CO}_{2}$, via the introduction of appropriate pre-functionalized ligands and/or the grafting of judiciously selected amine moieties on the open metal sites, and subsequently explore their potential for the $\mathrm{CCS}^{22,25-28}$ Nevertheless, only a limited number of functionalized MOFs, affording the $\mathrm{CO}_{2}$-chemisorption, showed promise for DAC and low-concentration $\mathrm{CO}_{2}$ capture from confined spaces $(<0.5 \%)^{22,26}$ Outwardly, it was intuited that chemisorption based sorbents are the foremost option for traces $\mathrm{CO}_{2}$ capture, ${ }^{8}$ and atypically put forward that physical adsorbents are prone to be ineffective for carbon capture at the low $\mathrm{CO}_{2}$ concentration of $400 \mathrm{ppm}$ due to their plausibly weak interactions with the adsorbed $\mathrm{CO}_{2}$ molecules. Contradictorily to this uncorroborated assumption, we recently published a series of $\mathrm{CO}_{2}$-selective $\mathrm{MOF}$ adsorbents, namely $\mathrm{MSiF}_{6}$ (pyrazine) $)_{2} \cdot 2 \mathrm{H}_{2} \mathrm{O}$ (referred to as SIFSIX-3-M where $\mathrm{M}$ $=\mathrm{Ni}, \mathrm{Cu}$ and $\mathrm{Zn}$ ), showing excellent $\mathrm{CO}_{2}$ selectivity and uptake at relatively low $\mathrm{CO}_{2}$ concentrations using solely the physisorption mechanism, ${ }^{17,30,31}$ and in some instances outclassing some of the amine grafted chemical sorbents. ${ }^{22}$ Nevertheless, extended exposure of SIFSIX-3-M adsorbents to water vapor resulted in an overtime lessening of their associated $\mathrm{CO}_{2}$ capture capabilities; suggesting their limited prospective deployment to mainly dry conditions.

\section{RESULTS AND DISCUSSIONS}

In order to extend the scope of this class of materials, we focused our efforts in better understanding the structure-property of these materials and as a result conceivably adjust/alter their molecular composition to enhance their water stability while maintaining or enhancing their carbon capture capabilities. The ability to construct the looked-for hydrolytically stable MOF with the desired $\mathrm{CO}_{2}$ adsorption properties will permit its potential use for carbon capture under practical humid conditions, and the subsequent elimination of the costly predrying step.

Accordingly, we conducted a structural analysis of the SIFSIX-3-M adsorbents with the aim to pinpoint the key structural features responsible for the noted unique $\mathrm{CO}_{2}$ capture properties. The key objective is to be able to derive a reasonable structure-property relationship that will assist and guide us in fine-tuning the resultant adsorbent structure to withstand the water vapor and concurrently enhance its intrinsic $\mathrm{CO}_{2}$ uptake and selectivity at traces $\mathrm{CO}_{2}$.

Appropriately, close examination of the SIFSIX-3-M adsorbents and their respective $\mathrm{CO}_{2}$ adsorption properties revealed the impact of the periodically aligned fluorine moieties in the contracted square-shaped channels, and that the F...F distance, dictating the channel size, is directly correlated to the strength of the $\mathrm{CO}_{2}$ interactions with the host framework. Namely, the comparison of SIFSIX-3-Zn $\left(\mathrm{Q}_{\mathrm{st}}=45 \mathrm{~kJ} \mathrm{~mol}^{-1}, \mathrm{~F} \ldots \mathrm{F}\right.$ dist. $=$ 6.784(1) $\AA)$, SIFSIX-3-Ni $\left(Q_{\mathrm{st}}=47 \mathrm{~kJ} . \mathrm{mol}^{-1}, \mathrm{~F} \ldots \mathrm{F}\right.$ dist. $=$ 6.694(1) $\AA$ ) and SIFSIX-3-Cu $\left(Q_{\mathrm{st}}=54 \mathrm{~kJ} . \mathrm{mol}^{-1}, \mathrm{~F} \ldots \mathrm{F}\right.$ dist. $=$ $6.483(1) \AA$ ) revealed that the $\mathrm{CO}_{2}$ is more strongly adsorbed at lower concentrations when the size of the square-shaped channel is further contracted, as a result of the shortened distance between the pendant fluorine moieties from diagonally adjacent $\left(\mathrm{SiF}_{6}\right)^{2-}$ pillars. ${ }^{17,30,31}$ Considerately, in addition to enabling the MOF pore system characteristics, contracted squareshaped channels with a periodically aligned proximal fluorine moieties, two other parameters were considered for the design and construction of the looked-for hydrolytically stable MOF for carbon capture. Specifically, we elected: i) to employ the $\mathrm{Ni}(\mathrm{II})$ as the octahedrally-coordinated metal node since the SIFSIX-3-Ni offers a shorter $\mathrm{M}-\mathrm{F}$ bond distance $\left(d_{\mathrm{M}-\mathrm{F}}=\right.$ $1.99(5) \AA)^{32}$ then the SIFSIX-3-Cu $\left(d_{\mathrm{M}-\mathrm{F}}=2.12(1) \AA\right)^{17}$ and thus prone to express the requisite water vapor tolerance, and ii) to substitute the $\left(\mathrm{SiF}_{6}\right)^{2-}$ pillar with an appropriate fluorinated inorganic pillar, offering a relatively stronger coordination bonds and the adequate nucleophilicity that can preclude the observed phase change in the SIFSIX-3-Cu, associated with the water molecule introduction within the $\mathrm{Cu}(\mathrm{II})$ coordination sphere. $^{31}$

Accordingly, the $\left(\mathrm{NbOF}_{5}\right)^{2-}$ was explored as a potential pillar to replace the original inorganic pillar, $\left(\mathrm{SiF}_{6}\right)^{2-}$, due its associated distinct attributes: (i) the larger size of $\mathrm{Nb}^{5+}$ imparts a longer $\mathrm{Nb}-\mathrm{F}$ bond length $(1.899(1) \AA)$ than the $\mathrm{Si}-\mathrm{F}$ bond (1.681(1) $\AA$ ), signifying the plausible reduction in the distance between the pendant proximal fluorine moieties within the channel; (ii) the higher nucleophile behavior of the $\left(\mathrm{NbOF}_{5}\right)^{2-}$ is anticipated to enhance the water stability of the resultant MOF (Figure 1).

Solvothermal reaction in a hydrofluoric acid aqueous solution containing a mixture of $\mathrm{Ni}\left(\mathrm{NO}_{3}\right)_{2} \cdot 6 \mathrm{H}_{2} \mathrm{O}, \mathrm{Nb}_{2} \mathrm{O}_{5}$ and pyrazine afforded violet square shaped crystals of NiNbOF $_{5}$ (pyrazine $)_{2} \cdot 2 \mathrm{H}_{2} \mathrm{O}$ (1) which we referred to as NbOFFIVE-1-Ni. Single crystal X-ray diffraction (SCXRD) study on a suitable single crystal of NbOFFIVE-1-Ni at 296 $\mathrm{K}$ revealed that the resultant compound crystallized in a tetragonal space group $I 4 / \mathrm{mcm}$ with unit cell parameters $a=b=$ 9.943(4) $\AA$ and $c=15.764(6) \AA$ (Table S1). The purity of the material was confirmed by a full pattern matching using the Le Bail $^{33}$ method implemented in Full prof software ${ }^{34}$ (Figure S1). As anticipated, the NbOFFIVE-1-Ni can be regarded as a 3periodic pcu-MOF based on the 2-periodic square grid, Ni(pyrazine $)_{2}$, bridged by the $\left(\mathrm{NbOF}_{5}\right)^{2-}$ pillars via the axial oxygen and fluorine centers. Each Ni(II) is octahedrally coordinated to four nitrogen centers, from four distinct pyrazine ligands, and one oxygen and one fluorine from the $\left(\mathrm{NbOF}_{5}\right)^{2-}$ pillar. It is to note that the assignment of one coordinating 
oxygen atom and one coordinating fluorine atom to the two apical positions in the pillar has been observed and validated in similar materials with supporting techniques. ${ }^{35-37}$ As expected, the NbOFFIVE-1-Ni encloses a relatively contracted square-shaped channels with a slightly smaller diameter of $3.210(8) \AA$ (derived from the distance between the pendant fluorine centers, F...F, and by taking account van der Walls radii) then the SIFSIX-3-Ni and SIFSIX-3-Cu adsorbents (3.694(1) $\AA$ and 3.483(1) $\AA$ respectively). It is to mention that the Ni...Ni distance (7.030(3) $\AA$ ) in the 2-periodic square grid, $\mathrm{Ni}$-(pyrazine) $)_{2}$, is preserved and it is the same in both, the NbOFFIVE-1-Ni and SIFSIX-3-Ni adsorbents.
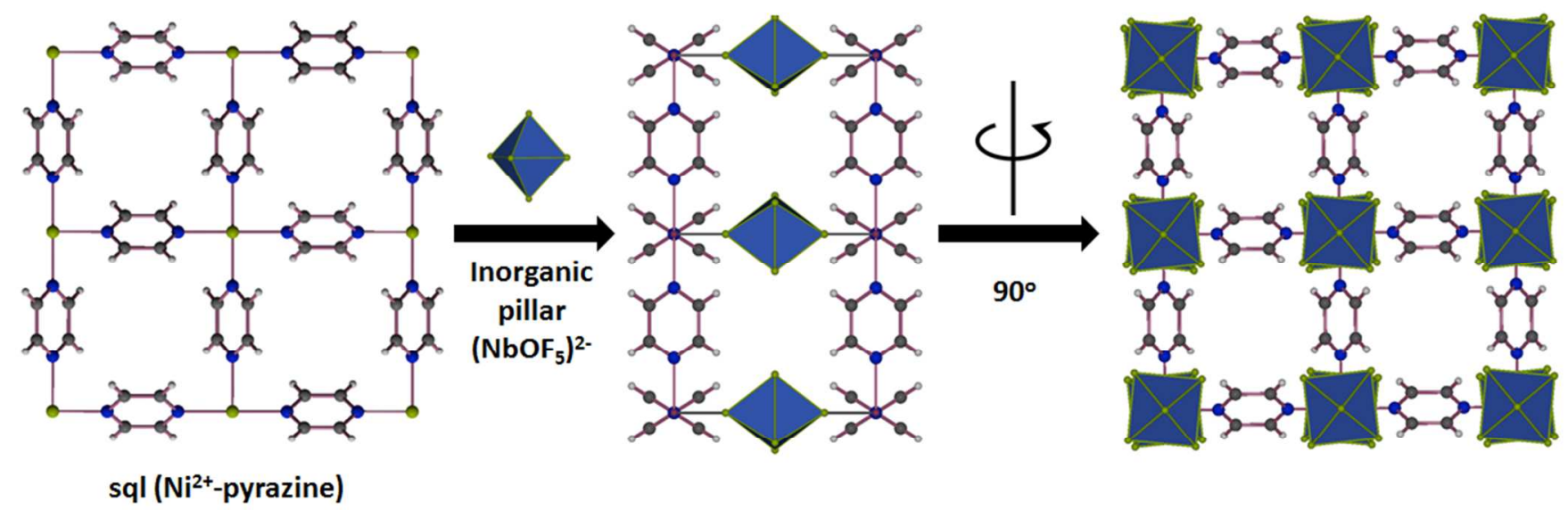

Figure 1. Structural representation of the NbOFFIVE-1-Ni: left, the 2-periodic square-grid layer constructed by linking Ni(II) with pyrazine ligands, middle, pillaring of square-grid layers by the $\left(\mathrm{NbOF}_{5}\right)^{2-}$ inorganic pillars, right, square-shaped channels in the resultant 3 periodic pcu-MOF, NbOFFIVE-1-Ni.

High thermal stability of the material was evaluated by TGA (Figure S5) and variable-temperature powder X-ray diffraction (PXRD) performed in the range of $25^{\circ} \mathrm{C}$ to $400{ }^{\circ} \mathrm{C}$, establishing that the material retained its crystallinity over the explored temperature range (Figure S3). Markedly, the hydrolytic stability of the material was confirmed by performing in-situ variable-humidity PXRD (Figure S4) and multiple water adsorption isotherms (Figure S6a) on the NbOFFIVE-1-Ni. The exceptional water stability was further confirmed by the conformity of the resultant $\mathrm{CO}_{2}$ isotherms before and after immersion of material in liquid water for 6 months (Figure S8). Moreover, NbOFFIVE-1-Ni showed excellent tolerance to hydrogen sulfide, a feature that is rarely proven for MOFs, as evidenced by the preservation of the material PXRD pattern after exposure to $\mathrm{H}_{2} \mathrm{~S}$ (Figure S2) and by performing $\mathrm{H}_{2} \mathrm{~S}$ adsorption isotherms (Figure $\mathrm{S} 6 \mathrm{~b}$ ). It is to state that $\mathrm{N}_{2}$ adsorption studies performed at $77 \mathrm{~K}$ on the activated material indicated as expected that the NbOFFIVE-1-Ni doesn't adsorb $\mathrm{N}_{2}$ at this cryogenic temperature. Conversely, the NbOFFIVE-1$\mathrm{Ni}$ adsorbs $\mathrm{CO}_{2}$ and accordingly this probe was employed to evaluate the porosity properties of this adsorbent. Specifically, the apparent surface area and the pore volume were derived from the $\mathrm{CO}_{2}$ adsorption isotherm at $273 \mathrm{~K}$ (Figure 2b) and estimated to be $280 \mathrm{~m}^{2} / \mathrm{g}$ and $0.095 \mathrm{~cm}^{3} / \mathrm{g}$, respectively. Distinctly, the NbOFFIVE-1-Ni provided the expected high affinity for $\mathrm{CO}_{2}$ at low concentrations as evidenced by the steepness in the $\mathrm{CO}_{2}$ adsorption isotherm and the attainment of the plateau at relatively very low $\mathrm{CO}_{2}$ pressures (Figure 2a, S7).

Detailed analysis of the $\mathrm{CO}_{2}$ adsorption isotherms associated to the NbOFFIVE-1-Ni and their comparison with a closely related material, SIFSIX-3-Ni, revealed an enhancement in the $\mathrm{CO}_{2}$ heat of the adsorption (Figure 2d) and most importantly a noticeable increase in the $\mathrm{CO}_{2}$ volumetric uptake at $400 \mathrm{ppm}$ of nearly $340 \%$. This remarkable $\mathrm{CO}_{2}$ uptake improvement, synonym of enhanced $\mathrm{CO}_{2}$-framework interac- tions, is directly correlated to the closer proximity of the pendant fluorine centers, decorating the square-shaped channels, in the case of the NbOFFIVE-1-Ni with an F...F distance of $3.210(8) \AA$ as compared to the 3.694(1) $\AA$ distance in the case of the SIFSIX-3-Ni.

Significantly, the NbOFFIVE-1-Ni adsorbent offers an even higher $\mathrm{CO}_{2}$ volumetric uptake at $400 \mathrm{ppm}$ than the best material so far for carbon capture at traces $\mathrm{CO}_{2}$ using physisorption mechanism, namely SIFSIX-3-Cu (Figure 2c). Precisely, the NbOFFIVE-1-Ni adsorbs a $51.4 \mathrm{~cm}^{3} / \mathrm{cm}^{3}(1.3 \mathrm{mmol} / \mathrm{g})$ of $\mathrm{CO}_{2}$ at $400 \mathrm{ppm}$ and $298 \mathrm{~K}$ as compared to a $44.6 \mathrm{~cm}^{3} / \mathrm{cm}^{3}$ for the SIFSIX-3-Cu, equivalent to a $15 \%$ increase than the best reported physical adsorbent to the best of our knowledge. In view of that, the NbOFFIVE-1-Ni can be regarded as the best physical adsorbent material for carbon capture at very low concentration of $\mathrm{CO}_{2}$ (traces) with the highest $\mathrm{CO}_{2}$ gravimetric and volumetric uptakes, driven mainly by physisorption mechanism. Excellent stability and the relatively mild condition for regeneration of the material also contribute to its prominence over other materials. The preeminent carbon capture potential of the NbOFFIVE-1-Ni, at $400 \mathrm{pm}$ of $\mathrm{CO}_{2}$, is even magnified at higher temperatures where the NbOFFIVE-1-Ni adsorbed the equivalence of an additional $63 \%$ more $\mathrm{CO}_{2}$ at $400 \mathrm{ppm}$ and $328 \mathrm{~K}$ than the SIFSIX-3-Cu adsorbent It to state that the volumetric uptake for well-known MOFs such as Mg-MOF-74 is comparatively very small at $400 \mathrm{ppm}\left(\approx 1.7 \mathrm{~cm}^{3} / \mathrm{cm}^{3}\right)$. In terms of gravimetric uptake both NbOFFIVE-1-Ni and SIFSIX-3- $\mathrm{Cu}$ have similar $\mathrm{CO}_{2}$ capacities and adsorb an equivalent of $43 \mathrm{~cm}^{3} \mathrm{STP} / \mathrm{g}$ at $1300 \mathrm{ppm}$ and $298 \mathrm{~K}$. This gravimetric uptake amounts to a notable $300 \%$ increase than the SAPO-34 $\left(\mathrm{Sr}^{2+}\right)$, the reference physical adsorbent for the $\mathrm{CO}_{2}$ removal in a long-duration crewed space exploration missions. Recently, a copper silicate (SGU-29) was reported to show a $\mathrm{CO}_{2}$ volumetric uptake of $26 \mathrm{~cm}^{3} / \mathrm{cm}^{3}$ and $40 \mathrm{~cm}^{3} / \mathrm{cm}^{3}$ at $\mathrm{CO}_{2}$ concentrations of 400 and $1000 \mathrm{ppm}$ (single gas adsorption), respectively. ${ }^{38}$ Noticeably, the $\mathrm{CO}_{2}$ volumetric and gravimetric 
uptakes of this purely inorganic $\mathrm{CO}_{2}$-adsorbent are much lower than NbOFFIVE-1-Ni at very low $\mathrm{CO}_{2}$ pressures.

In order to gain a better insight on the structure-property relationship leading to the unusually strong physisorption of $\mathrm{CO}_{2}$ and the subsequent improvement in the $\mathrm{CO}_{2}$ adsorption capabilities of the NbOFFIVE-1-Ni, we succeeded in solving the crystal structure of the NbOFFIVE-1-Ni in the presence $\mathrm{CO}_{2}$ and most importantly localized the adsorbed $\mathrm{CO}_{2}$ molecules. Purposely, we collected a SCXRD data on a degassed crystal of NbOFFIVE-1-Ni under 1 bar dry $\mathrm{CO}_{2}$ atmosphere at $298 \mathrm{~K}$. The structure containing $\mathrm{CO}_{2}$ molecules was solved in
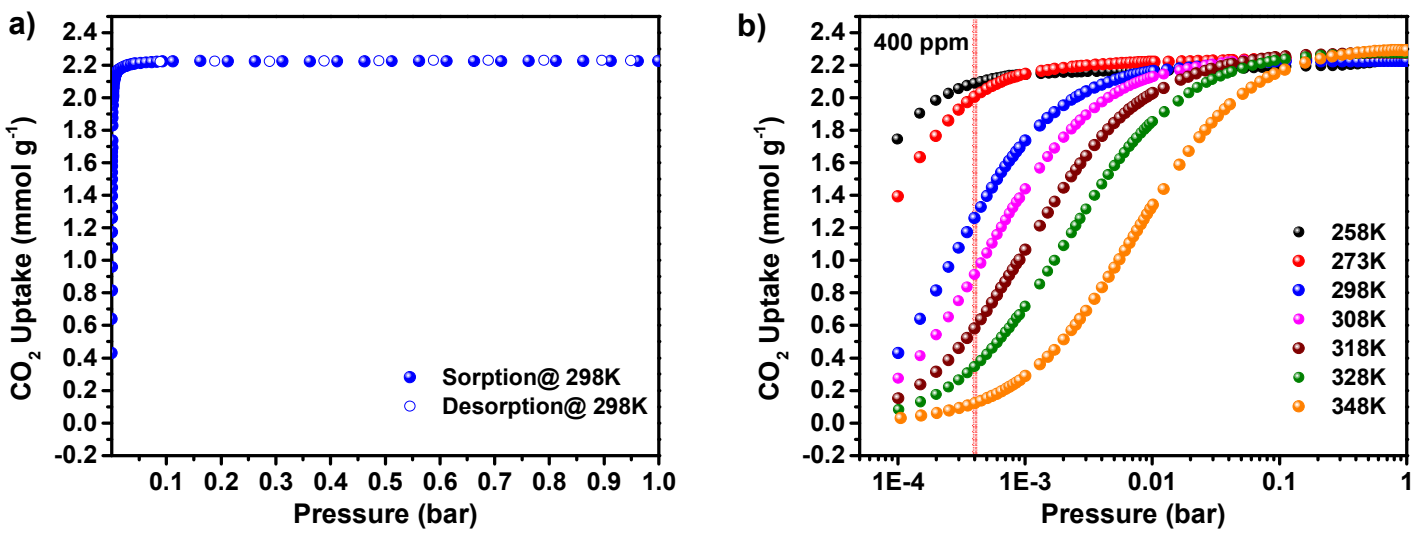

c)

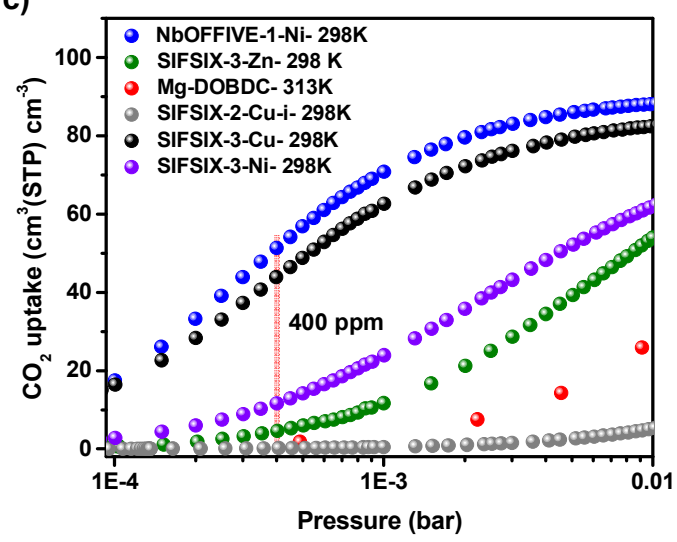

d)

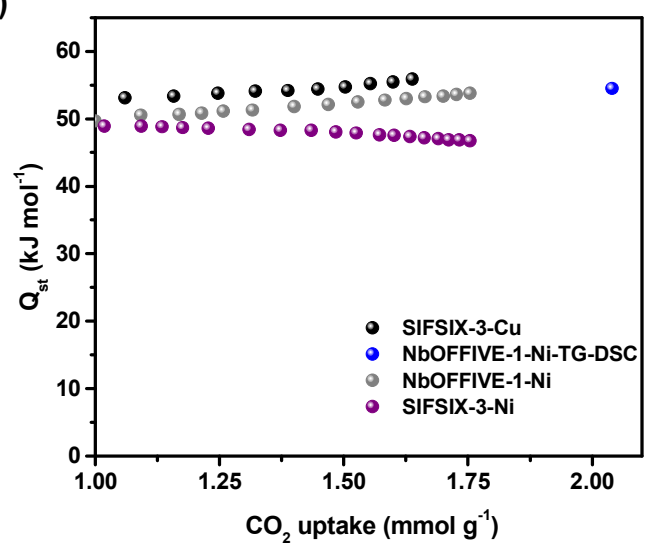

Figure 2. a) $\mathrm{CO}_{2}$ adsorption isotherm for NbOFFIVE-1-Ni up to 1 bar and $298 \mathrm{~K}$. b) $\mathrm{CO}_{2}$ adsorption isotherms for NbOFFIVE-1-Ni at different temperatures. c) Comparison of the $\mathrm{CO}_{2}$ uptake at low pressures between the NbOFFIVE-1-Ni and the SIFSIX family as well as the Mg-MOF-74, one of the best MOF for low pressure $\mathrm{CO}_{2}$ adsorption. d) $\mathrm{CO}_{2}$ heat of adsorption for NbOFFIVE-1-Ni as compared to SIFSIX-3-Ni and SIFSIX-3-Cu, determined using multiple $\mathrm{CO}_{2}$ adsorption isotherms as well as TG-DSC measurements.

the same space group as the as-synthesized compound, hosting water molecules, namely a tetragonal space group $I 4 / \mathrm{mcm}$ with unit cell parameters $a=b=9.903(1) \AA$ and $c=15.720(2)$ $\AA$ and formulated as $\mathrm{NiNbOF}_{5}(\text { pyrazine })_{2} \cdot 0.84\left(\mathrm{CO}_{2}\right)(2)(\mathrm{Ta}-$ ble S2).

The interpretation of the Fourier difference data allows us to clearly localize the $\mathrm{CO}_{2}$ molecules within the square-shaped channels of the NbOFFIVE-1-Ni.0.84CO 2 structure. Interestingly, the $\mathrm{CO}_{2}$ molecule occupy a high energetically favorable position, where the electropositive carbon of the $\mathrm{CO}_{2}$ is surrounded by four electronegative fluorine centers from four distinct $\left(\mathrm{NbOF}_{5}\right)^{2-}$ pillars $\left(\mathrm{F} \cdots \mathrm{C}_{\mathrm{CO} 2}\right.$ distance $\left.=3.050(8) \AA\right)$ and the electronegative oxygen atoms of the $\mathrm{CO}_{2}$ are surrounded by pyrazine hydrogens $(\mathrm{C}-\mathrm{H}$...O distance $=2.99 \AA$, angle $=$ $\left.117^{\circ}\right)$ as depicted in Figure 3. It is worth to mention that the ${ }^{\mathrm{F}} \cdots \mathrm{C}_{\mathrm{CO} 2}$ distance (ca. 3.050(8) $\AA$ ) in the case of the NbOFFIVE-1-Ni.0.84CO $\mathrm{CO}_{2}$ is less than the sum of the $\mathrm{C}$ and $\mathrm{F}$ van der Waals radii, supporting the $\mathrm{CO}_{2}$ molecules strong in- teractions with the host framework. These interactions are relatively stronger that those observed in the case of the SIFSIX-3-Ni, structure derived from the PXRD data, where the distance $\mathrm{F}^{\cdots} \mathrm{C}_{\mathrm{CO} 2}$ is found to be equal to $3.302 \AA{ }^{32}$ a distance clearly larger than the $\mathrm{C}$ and $\mathrm{F}$ van der Waals radii and confirming the relatively weaker $\mathrm{CO}_{2}$-framework interactions than in the case of the $\mathrm{CO}_{2}$ adsorbed in the NbOFFIVE-1-Ni adsorbent.

It can be inferred from the crystal structure that the presence at close proximity of relatively strong and concurrent complementary interactions created an ideal and energetically favorable 'sweet spot' for the adsorption of $\mathrm{CO}_{2}$, and proffered unique $\mathrm{CO}_{2}$ capture features to the NbOFFIVE-1-Ni adsorbent. The presence of highly favorable $\mathrm{CO}_{2}$-framework interactions in case of NbOFFIVE-1-Ni is also evidenced by the steady and marked high $\mathrm{CO}_{2}$ heat of adsorption (Figures $2 \mathrm{~d}$, $\mathrm{S} 12)$. The $\mathrm{CO}_{2}$ heat of adsorption for the NbOFFIVE-1-Ni was determined using $\mathrm{CO}_{2}$ adsorption isotherms at variable 
temperature (Figure $2 \mathrm{~b}$ and S7) and further supported by the direct TG-DSC measurement (Figure 2d, S12).

In order to assert the potential of the NbOFFIVE-1-Ni as a proper physical-adsorbent for carbon capture at dilute $\mathrm{CO}_{2}$ concentrations, we performed mixed-gas experiments under conditions akin to the real world carbon capture in confined spaces or from ambient air. A series of cyclic $\mathrm{CO}_{2}(1 \%) / \mathrm{N}_{2}$ (99\%) column breakthrough experiments at $298 \mathrm{~K}$ were performed in the presence and absence of water vapor (both dry and humid conditions) (Figure 4). The breakthrough time under dry conditions for a $1 \% \mathrm{CO}_{2}$ in the gas stream with the flow rate of $10 \mathrm{cc} / \mathrm{min}$ revealed a remarkable retention of 415 $\mathrm{min} / \mathrm{g}$ that is equivalent to the adsorbed $\mathrm{CO}_{2}$ equaling 8.2 $\mathrm{wt} \%$.

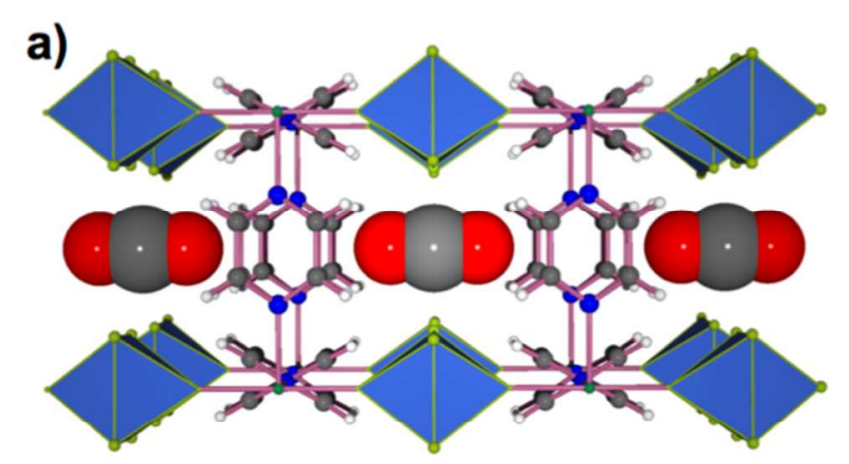

b)

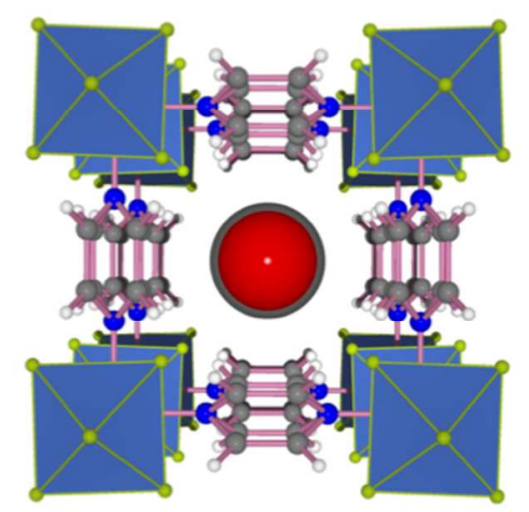

Figure 3. Direct visualization of $\mathrm{CO}_{2}$ molecules inside the crystal structure of the NbOFFIVE-1-Ni highlighting the highly favorable arrangement of the $\mathrm{CO}_{2}$ molecules within the contracted square-shaped channels along [010] and [001].

Certainly, the presence of humidity $(75 \% \mathrm{RH})$ did not significantly alter the $\mathrm{CO}_{2}$ breakthrough time $(283 \mathrm{~min} / \mathrm{g}$, uptake of $5.6 \mathrm{wt} \%$ ). In addition, the $\mathrm{CO}_{2}$ uptakes in dry and humid streams were conserved as proven by the reproducible data from multiple cycle breakthrough experiments, where prior to each new cycle the adsorbent was fully reactivated at $378 \mathrm{~K}$ (Figure S10, S11). Interestingly, the water vapor was retained in the column for $680 \mathrm{~min} / \mathrm{g}$ which is equivalent to a water uptake of $13.8 \mathrm{wt} \%$. It is to state that the noticeable adsorbed water uptake did not jeopardize the carbon capture capabilities of the NbOFFIVE-1-Ni and suggests a rare simultaneous adsorption of water and $\mathrm{CO}_{2}$ in contrast to most MOFs and zeolites. Appropriately, column breakthrough experiments for very dilute $\mathrm{CO}_{2}$ concentrations (i.e. $1000 \mathrm{ppm} \mathrm{CO}_{2}$ ), with a flow rate of $20 \mathrm{~cm}^{3} / \mathrm{min}$, showed that $\mathrm{CO}_{2}$ is retained in the column for $1880 \mathrm{~min} / \mathrm{g}$ with an equivalent uptake of $7.4 \mathrm{wt} \%$ (Figure S9).

Finally, in order to position the carbon capture performance of the NbOFFIVE-1-Ni vis-à-vis the existing technologies, and in comparison with key benchmark materials (both chemical and physical adsorbents) deployed in real-world applications or regarded to offer great promise, we complied and assessed each material $\mathrm{CO}_{2}$ removal capacity at around $1000 \mathrm{ppm} \mathrm{CO}_{2}$ for 1 day against the given material associated $\mathrm{CO}_{2}$ heat of adsorption. For practical reasons we assumed that all sorbent are fully recyclables with the exception of the lithium hydroxide $(\mathrm{LiOH})$, a non-recyclable sorbent. ${ }^{39}$

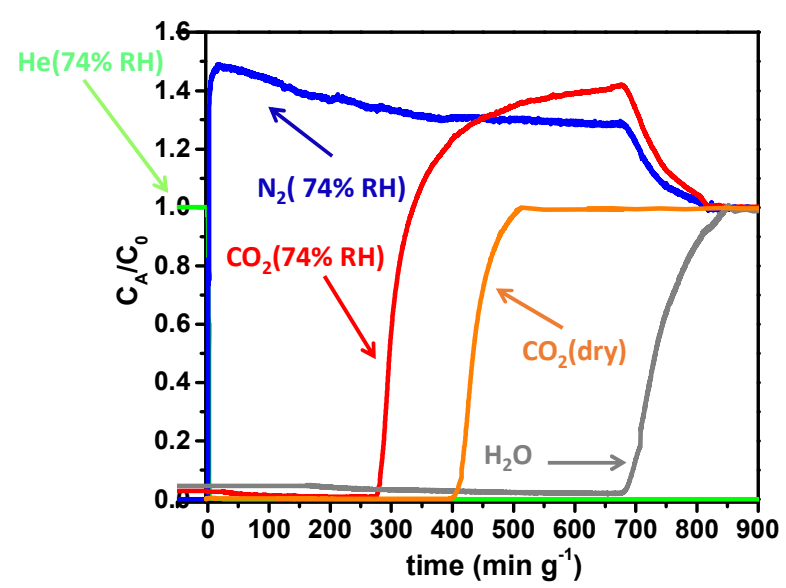

Figure 4. Column breakthrough tests for the NbOFFIVE-1-Ni with the mixed-gas $\mathrm{CO}_{2} / \mathrm{N}_{2}(1 \% / 99 \%)$ at 1 bar and $298 \mathrm{~K}$ in both dry and humid conditions $\left(10 \mathrm{~cm}^{3} / \mathrm{min}\right.$ flow rate).

For comparison purposes, we arbitrarily fixed and adopted he full adsorption-desorption cycle to be at $60 \mathrm{~min}$ (24 cycles a day) and the evaluation based on the requirements for the $\mathrm{CO}_{2}$ scrubbing in confined spaces, specifically $1 \mathrm{~kg}$ of $\mathrm{CO}_{2}$ captured per day and per person.

Interestingly, as depicted in Figure 5, the NbOFFIVE-1-Ni exhibits the best compromise between the carbon capture capacity and the required heat for regeneration. Precisely, at 1000 ppm $\mathrm{CO}_{2}$, the NbOFFIVE-1-Ni offers the highest $\mathrm{CO}_{2}$ capacity in 1 day ( 24 cycles) associated with the optimal heat of adsorption (dictating the required energy for regeneration) than all the evaluated sorbents such as $\mathrm{LiOH}$, liquid amine, amine supported solids, zeolites 5A $\left(\mathrm{Ca}^{2+}\right)$, SAPO-34 $\left(\mathrm{Sr}^{2+}\right)$ and the recently reported copper silicate (SGU-29). The $\mathrm{CO}_{2}$ uptake at $1000 \mathrm{ppm}\left(\mathrm{kg} \cdot \mathrm{kg}^{-1} \cdot \mathrm{day}^{-1}\right)$ was calculated from mixed gas breakthrough experiment for the NbOFFIVE-1-Ni adsorbent and from the reported adsorption isotherms or reported data for other materials. It is to be noted that $\mathrm{CO}_{2}$ uptake obtained from dynamic conditions such as breakthrough adsorption column is always slightly lower than $\mathrm{CO}_{2}$ uptake obtained from adsorption isotherms (equilibrium condition). These values, associated to one cycle, were multiplied by 24 (1 hour cycle) in order to obtain a given material daily performance and derive a relative comparison between evaluated materials per one day. 


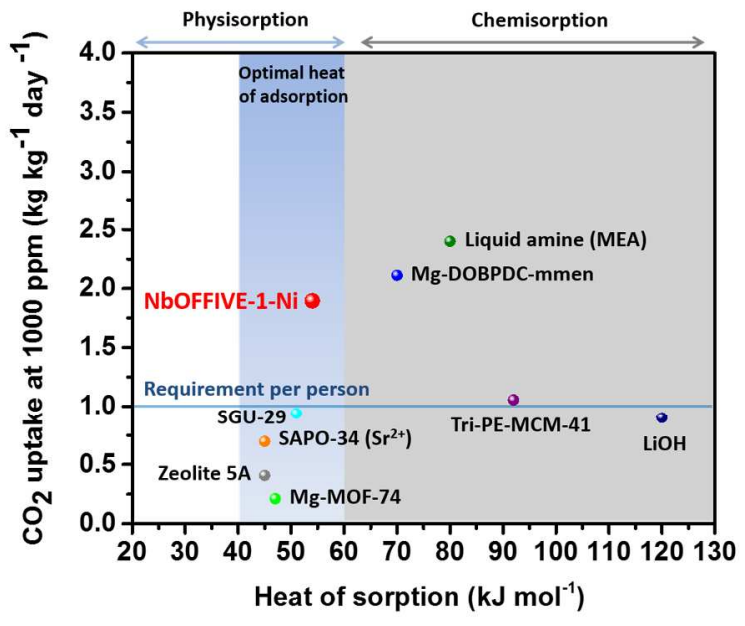

Figure 5. Heat of adsorption- $\mathrm{CO}_{2}$ uptake (at $1000 \mathrm{ppm}$ for 1 day) trade-off for NbOFFIVE-1-Ni as compared to benchmark and newly developed materials. At the exception of $\mathrm{LiOH}$, the $\mathrm{CO}_{2}$ uptake for 1 day for all the materials was calculated assuming a 60 min adsorption-desorption cycle.

Evidently, although this is a simplified analysis, assuming 24 cycles per day and not taking into account the rate of $\mathrm{CO}_{2}$ adsorption/desorption and many other constraints relevant to real processes, particularly for amine supported materials and chemical sorbents, ${ }^{14,40}$ it portrays and places the NbOFFIVE$1-\mathrm{Ni}$ as a prospective physical-adsorbent for an effective and energy-efficient $\mathrm{CO}_{2}$ capture in confined spaces and from atmospheric air.

Work is in progress to assess the related economics and technicalities associated with the potential deployment of the NbOFFIVE- 1-Ni adsorbent in practical carbon capture applications from atmosphere and in confined spaces using rapid thermal swing adsorption.

\section{CONCLUSIONS}

In summary, the close examination of the structural features of the SIFSIX adsorbent family permitted the election of a bulkier and a relatively nucleophilic inorganic pillar, namely the $\left(\mathrm{NbOF}_{5}\right)^{2-}$ instead of the original $\left(\mathrm{SiF}_{6}\right)^{2-}$ pillar, and the successful practice of reticular chemistry for the construction a hydrolytically stable pcu-MOF, NbOFFIVE-1-Ni, with contracted square-channels decorated with proximal fluorine moieties and ideal for carbon capture at vey dilute $\mathrm{CO}_{2}$ concentrations. To the best of our knowledge, the reported NbOFFIVE$1-\mathrm{Ni}$ stands as the best physical-adsorbent material for $\mathrm{CO}_{2}$ capture from atmospheric and confined spaces, driven mainly by physical adsorption. Specifically, in terms of the $\mathrm{CO}_{2}$ adsorption energetics and uptakes, the NbOFFIVE-1-Ni has the highest uptake for $\mathrm{CO}_{2}$ at $400 \mathrm{ppm}$ with associated relatively optimal energy for regeneration. From the perspective of the carbon capture in a confined space, air removal viewpoint, the NbOFFIVE-1-Ni offers a $300 \%$ higher $\mathrm{CO}_{2}$ gravimetric and volumetric uptakes then the SAPO-34 $\left(\mathrm{Sr}^{2+}\right)$, the reference physical adsorbent for the $\mathrm{CO}_{2}$ removal in a long-duration crewed space exploration missions, with equivalent $\mathrm{CO}_{2}$ adsorption energetics.

Direct observation and localization of the adsorbed $\mathrm{CO}_{2}$ molecules within the adsorbent channels, using single crystal X-ray diffraction data, gives valuable insights on the nature of the $\mathrm{CO}_{2}$-framework interactions governing the high affinity of the NbOFFIVE-1-Ni for $\mathrm{CO}_{2}$ even at very dilute concentrations. This unique structural insight will certainly pave the way to the design and the construction of new and practical physical adsorbents with a similar $\mathrm{CO}_{2}$ affinity and a further improved $\mathrm{CO}_{2}$ uptake. Practically, unlike many other MOFs, the NbOFFIVE-1-Ni offers great potential to be easily synthesized in large quantities ( $\mathrm{g}$ to $\mathrm{kg}$ ) and in a cost-effective manner; and thus placing this physical adsorbent in the right track for large-scale deployment and plausible commercialization. Work is in progress to scale-up and test this MOF at a pilot scale.

\section{EXPERIMENTAL SECTION}

\section{Materials and methods.}

Elemental Analyses for $\mathrm{C}, \mathrm{H}$ and $\mathrm{N}$ were carried out on a ThermoFinnigan Apparatus. Thermal gravimetric analyses (TGA) were performed under $\mathrm{N}_{2}$ flow $(25 \mathrm{ml} / \mathrm{min})$ with a heating rate of $5{ }^{\circ} \mathrm{C} / \mathrm{min}$ using a TA Q500 apparatus. Enthalpy of adsorption for $\mathrm{CO}_{2}$ and $\mathrm{H}_{2} \mathrm{O}$ was measured using SENSYS evo TG-DSC from Setaram Instrumentation that can carry out simultaneous high resolution DSC and TGA experiments. In a typical experiment, the sample was activated in-situ at $105{ }^{\circ} \mathrm{C}$ under continuous dry $\mathrm{N}_{2}$ flow at the rate of $15 \mathrm{ml} / \mathrm{min}$. For sorption experiment, baseline was obtained under dry $\mathrm{N}_{2}$ flow at the rate of $15 \mathrm{ml} / \mathrm{min}$ at $25{ }^{\circ} \mathrm{C}$. $\mathrm{CO}_{2}$ or humid $\mathrm{N}_{2}$ was connected at auxiliary gas port and gas was changed from $\mathrm{N}_{2}$ to $\mathrm{CO}_{2} /$ humid $\mathrm{N}_{2}$ exactly after 1 hour and TGA and DSC signal were monitored for few hours to obtain uptake and heat of sorption respectively. The powder X-ray diffraction patterns and the variable humidity powder X-ray diffraction patterns (VH-PXRD) were collected over the $2 \theta$ range $4-40^{\circ}$ on a high resolution PANalytical X'Pert MPD-PRO diffractometer with $\mathrm{CuK} \alpha 1$ radiation $(\lambda=1.5406 \AA, 45 \mathrm{kV} / 40 \mathrm{~mA})$. Variable Temperature Powder X-ray Diffraction (VT-PXRD) patterns measurements were collected on a PANalyticalX'Pert MPD-PRO $\mathrm{X}$-ray diffractometer equipped with an Anton-Parr $\mathrm{CHC}+$ variable temperature stage. Measurements were performed at $45 \mathrm{kV}, 40$ $\mathrm{mA}$ for $\mathrm{Cu} \mathrm{K \alpha}(\lambda=1.5418 \AA)$ with a scan speed of $1.0^{\circ} / \mathrm{min}$ and a step size of $0.02^{\circ}$ in $2 \theta$. Samples were placed under vacuum during analysis and the sample was held at the designated temperatures for at least 15 minutes between each scan.

\section{Synthesis of NbOFFIVE-1-Ni}

All reagents were used as received from commercial suppliers without further purification: $\mathrm{Ni}\left(\mathrm{NO}_{3}\right)_{2} \cdot 6 \mathrm{H}_{2} \mathrm{O}$ (Acros), $\mathrm{Nb}_{2} \mathrm{O}_{5}$ (Aldrich), Pyrazine (Aldrich), HF (Aldrich). Pyrazine (384.40 mg, $4.80 \mathrm{mmol}), \mathrm{Ni}\left(\mathrm{NO}_{3}\right)_{2} \cdot 6 \mathrm{H}_{2} \mathrm{O}(174.50 \mathrm{mg}, 0.60 \mathrm{mmol}), \mathrm{Nb}_{2} \mathrm{O}_{5}$ (79.70 mg, $0.30 \mathrm{mmol})$ and $\mathrm{HF}_{\mathrm{aq}} 48 \%(0.26 \mathrm{ml}, 7.15 \mathrm{mmol})$ were mixed in a $20 \mathrm{ml}$ Teflon liner. The mixture was diluted with $3 \mathrm{ml}$ deionized water and then the autoclave was sealed and heated to $130{ }^{\circ} \mathrm{C}$ for $24 \mathrm{~h}$. After cooling down the reaction mixture to room temperature, the resultant violet square-shaped crystals, suitable for single crystal X-ray structure determination, were collected by filtration, washed with ethanol and dried in air. Elemental analysis: N\%: 11.88 (theo: 12.21), C\%: 20.58 (theo: 20.54), $\mathrm{H} \%: 2.54$ (theo: 2.64), $\mathrm{O} \%: 11.42$ (theo: 10.46). $\mathrm{C}_{8} \mathrm{H}_{12} \mathrm{O}_{2} \mathrm{~N}_{4} \mathrm{~F}_{5} \mathrm{NiNb}$ $\mathrm{NiNbOF}_{5}(\text { pyr })_{2} \cdot\left(\mathrm{H}_{2} \mathrm{O}\right)_{2}$ (called NbOFFIVE-1-Ni) was activated at $105{ }^{\circ} \mathrm{C}$ for 12 hours under high vacuum (3milliTorrs) before each adsorption experiment.

\section{ASSOCIATED CONTENT}

\section{Supporting Information}


PXRD, additional structural figures, sorption, and single-crystal $\mathrm{X}$-ray diffraction data (CIF). This material is available free of charge via the Internet at http://pubs.acs.org

\section{AUTHOR INFORMATION}

\section{Corresponding Author}

*mohamed.eddaoudi@kaust.edu.sa

\section{Notes}

The authors declare no competing financial interests.

\section{ACKNOWLEDGMENT}

Research reported in this publication was supported by King Abdullah University of Science and Technology (KAUST) under $\mathrm{CCF} / 1 / 1972-02-01, \mathrm{CCF} / 1 / 1972-6-01$ and $\mathrm{CCF} / 1 / 1972-8-01$.

\section{REFERENCES}

(1) U.S. Department of Energy. Materials for Separation Technology: Energy and emission Reduction Opportunities, 2005, DOI: 10.2172/1218755

(2) Al-Maythalony, B. A.; Shekhah, O.; Swaidan, R.; Belmabkhout, Y. Pinnau, I.; Eddaoudi, M. J. Am. Chem. Soc. 2015, 137, 1754.

(3) Belmabkhout, Y.; Guillerm, V.; Eddaoudi, M. Chem. Eng. J. 2016, 296, 386 .

(4) Choi, S.; Drese, J. H.; Eisenberger, P. M.; Jones, C. W. Environ. Sci. \& Technol. 2011, 45, 2420.

(5) Eisaman, M. D.; Alvarado, L.; Larner, D.; Wang, P.; Garg, B.; Littau, K. A. Energy Environ. Sci. 2011, 4, 1319.

(6) Goeppert, A.; Czaun, M.; Surya Prakash, G. K.; Olah, G. A. Energy Environ. Sci. 2012, 5, 7833.

(7) Keith, D. W. Science 2009, 325, 1654

(8) Lackner, K. S.; Brennan, S.; Matter, J. M.; Park, A.-H. A.; Wright, A.; van der Zwaan, B. Proc. Natl. Acad. Sci. USA. 2012, 109, 13156.

(9) Mahmoudkhani, M.; Heidel, K. R.; Ferreira, J. C.; Keith, D. W.; Cherry, R. S. Energy Procedia 2009, 1, 1535 .

(10) Sayari, A.; Belmabkhout, Y.; Serna-Guerrero, R. Chem. Eng. J. 2011, 171,760 .

(11) Stolaroff, J. K.; Keith, D. W.; Lowry, G. V. Environ. Sci. \& Technol. 2008 $42,2728$.

(12) Carey, R.; Gomezplata, A.; Sarich, A. Ocean Eng. 1983, 10, 227.

(13) Dallbauman, L. A.; Finn, J. E. in Adsorption and Its Applications in Industry and Environmental Protection: Applications in Environmental Protection, Part B (Ed.: A. Dąbrowski), Elsevier, New York 1999, 120, 455471.

(14) Belmabkhout, Y.; Serna-Guerrero, R.; Sayari, A. Chem. Eng. Sci. 2010, 65,3695

(15) Xue, D.-X.; Cairns, A. J.; Belmabkhout, Y.; Wojtas, L.; Liu, Y.; Alkordi, M. H.; Eddaoudi, M. J. Am. Chem. Soc. 2013, 135, 7660.

(16) Sayari, A.; Belmabkhout, Y.; Da'na, E. Langmuir 2012, 28, 4241.
(17) Shekhah, O.; Belmabkhout, Y.; Chen, Z.; Guillerm, V.; Cairns, A.; Adil, K.: Eddaoudi, M. Nat. Commun. 2014, 5, 4228

(18) García-Ricard, O. J.; Arévalo-Hidalgo, A. G.; Yu, M.; Almodóvar-Arbelo, N. E.; Varghese, M.; Mulloth, L.; Luna, B.; Hernández-Maldonado, A. J. Separ. Sci. Technol. 2014, 49, 490

(19) Mulloth, L. M.; Finn, J. E. Carbon dioxide adsorption on a $5 A$ zeolite designed for $\mathrm{CO}_{2}$ removal in spacecraft cabins, NASA Ames Research Center, NASA/TM-1998-208752National Technical Information Service, USA, 1998

(20) Eddaoudi, M.; Kim, J.; Rosi, N.; Vodak, D.; Wachter, J.; O'Keeffe, M.; Yaghi, O. M. Science 2002, 295, 469.

(21) Ferey, G. Serre, C. Chem. Soc. Rev. 2009, 38, 1380

(22) Fracaroli, A. M.; Furukawa, H.; Suzuki, M.; Dodd, M.; Okajima, S.; Gándara, F.; Reimer, J. A.; Yaghi, O. M. J. Am. Chem. Soc. 2014, 136, 8863. (23) Guillerm, V.; Weseliński, Ł. J.; Belmabkhout, Y.; Cairns, A. J.; D'Elia, V.; Wojtasłukasz; Adil, K.; Eddaoudi, M. Nat. Chem. 2014, 6, 673.

(24) Horike, S.; Shimomura, S.; Kitagawa, S. Nat. Chem. 2009, 1, 695.

(25) Li, J.-R.; Ma, Y.; McCarthy, M. C.; Sculley, J.; Yu, J.; Jeong, H.-K.; Balbuena, P. B.; Zhou, H.-C. Coord. Chem. Rev. 2011, 255, 1791.

(26) McDonald, T. M.; Lee, W. R.; Mason, J. A.; Wiers, B. M.; Hong, C. S.; Long, J. R. J. Am. Chem. Soc. 2012, 134, 7056.

(27) McDonald, T. M.; Mason, J. A.; Kong, X.; Bloch, E. D.; Gygi, D.; Dani, A.; Crocella, V.; Giordanino, F.; Odoh, S. O.; Drisdell, W. S.; Vlaisavljevich, B.; Dzubak, A. L.; Poloni, R.; Schnell, S. K.; Planas, N.; Lee, K.; Pascal, T.; Wan, L. F.; Prendergast, D.; Neaton, J. B.; Smit, B.; Kortright, J. B.; Gagliardi, L.; Bordiga, S.; Reimer, J. A.; Long, J. R. Nature 2015, 519, 303.

(28) Xiang, S.; He, Y.; Zhang, Z.; Wu, H.; Zhou, W.; Krishna, R.; Chen, B. Nat. Commun. 2012, 3, 954

(29) Zhang, M.; Chen, Y.-P.; Bosch, M.; Gentle, T.; Wang, K.; Feng, D. Wang, Z. U.; Zhou, H.-C. Angew. Chem. Int. Ed. 2014, 53, 815

(30) Nugent, P.; Belmabkhout, Y.; Burd, S. D.; Cairns, A. J.; Luebke, R.; Forrest, K.; Pham, T.; Ma, S.; Space, B.; Wojtas, L.; Eddaoudi, M.; Zaworotko, M. J. Nature 2013, 495, 80.

(31) Shekhah, O.; Belmabkhout, Y.; Adil, K.; Bhatt, P. M.; Cairns, A. J.; Eddaoudi, M. Chem. Commun. 2015, 51, 13595.

(32) Elsaidi, S. K.; Mohamed, M. H.; Schaef, H. T.; Kumar, A.; Lusi, M. Pham, T.; Forrest, K. A.; Space, B.; Xu, W.; Halder, G. J.; Liu, J.; Zaworotko, M. J.; Thallapally, P. K. Chem. Commun. 2015, 51, 15530.

(33) Le Bail, A.; Duroy, H.; Fourquet, J. L. Mater. Res. Bull. 1988, 23, 447.

(34) Rodriguez-Carvajal, J. Abstracts of the Satellite. Meeting on Powder Diffraction of the XV Congress of the IUCr, 1990, 127.

(35) Gautier, R.; Donakowski, M. D.; Poeppelmeier, K. R. J. Solid State Chem. 2012, 195, 132.

(36) Izumi, H. K.; Kirsch, J. E.; Stern, C. L.; Poeppelmeier, K. R. Inorg. Chem. 2005, 44, 884.

(37) Maggard, P. A.; Kopf, A. L.; Stern, C. L.; Poeppelmeier, K. R. CrystEngComm 2004, 6, 452.

(38) Datta, S. J.; Khumnoon, C.; Lee, Z. H.; Moon, W. K.; Docao, S.; Nguyen, T. H.; Hwang, I. C.; Moon, D.; Oleynikov, P.; Terasaki, O.; Yoon, K. B. Science 2015, 350, 302

(39) Norfleet, W. Horn, W. Carbon Dioxide scrubbing capabilities of two new non-Powdered technologies. MSMRL Report N0. TR1228, Naval Submarine Medical Research Laboratory, United Kingdom, 2003.

(40) Belmabkhout, Y.; Serna-Guerrero, R.; Sayari, A. Adsorption 2011, 17, 395. 
$\mathrm{CO}_{2}$ physisorption as the new effective and efficient path for traces $\mathrm{CO}_{2}$ removal: A deliberately designed hydrolytically stable MOF, NbOFFIVE-1-Ni, was found to possess the highest $\mathrm{CO}_{2}$ volumetric and gravimetric uptake at 400 ppm for any physical adsorbents.

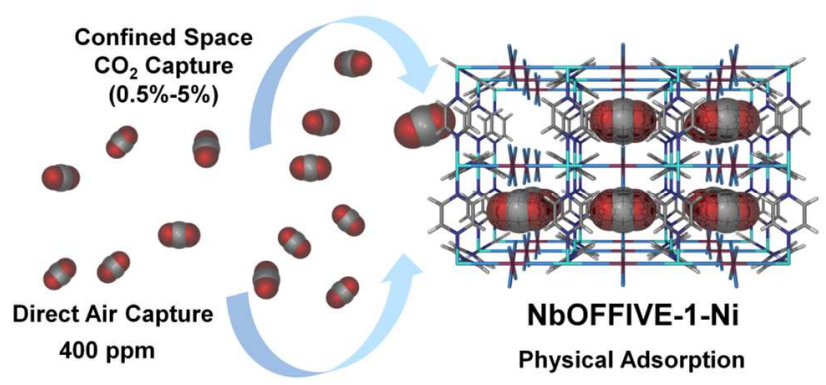

16

17

18

19

20

21

22

23

24

25

26

27

28

29

30

31

32

33

34

35

36

37

38

39

40

41

42

43

44

45

46

47

48

49

50

51

52

53

54

55

56

57

58

59

60 